
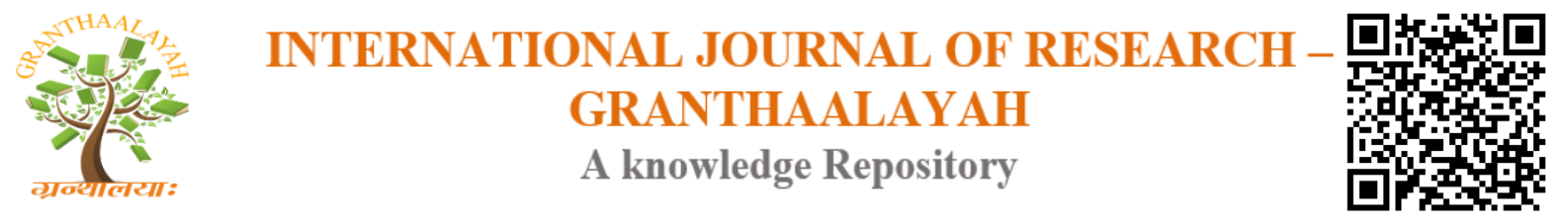

Management

\title{
NETWORKING AND RISK -TAKING ON GROWTH OF SELECTED KENYA EXPORT FIRMS: AN ANALYSIS
}

\author{
Joyce Achola Ogundo ${ }^{1}$, Prof Peter Ki bas ${ }^{2}$, Dr Robert Otuya ${ }^{3}$ \\ ${ }^{1} \mathrm{PhD}$ (Candidate) Business Administration (Entrepreneurship), Secretary, Trade State Depart \\ Ministry of Industry, Trade and Co-operative for Trade \\ ${ }^{2}$ Baraton University, Kenya \\ ${ }^{3}$ University of Eldoret, Kenya
}

\begin{abstract}
Networking and Risk_Taking on Growth of of Export Firms have such an important role in global success and become more useful overtime. Networking and Risk _Taking on Growth of Export Firms have not been addressed in full, their challenges such as lack of Literature on Risk -Taking on Export Firms is very scanty and hence not exhaustive. This Research attempts to utilise Sample size of 169 ,adopted from thesis on in Selected Kenya Export Firms .The Research employed Analysis of Moment Structures to compare Networking and Risk_Taking to Analyse Growth of Export Firms Selected Kenya Export Firms, GFI was utilized to determine model goodness of fit, Multiple Group Model Comparisons. Finding indicate that the two Models of Networking and Risk_Taking differ, it was clear that equal Standardized Regression weight model results were substantially worse on overall model fit, specifically on Risk -Taking. A comparative analysis identified issues on Networking which proved to be useful as a construct of Growth of Export Firms for its application on Export Firms however some limitations in terms of: Error difference, Low model goodness of fit were faced by the Risk-Taking. The study concludes that the dimensions of Networking were positively related to export firm growth. The study recommends: development of entrepreneurship policy, the public sector needs to focus attention on developing networking opportunities among employees. Export firms should undertake research on RiskTaking and segments that can support firm growth.
\end{abstract}

Keywords: Growth; Networking; Multiple Group Model Comparisons.

Cite This Article: Joyce Achola Ogundo, Prof Peter Ki bas, and Dr Robert Otuya. (2018). "NETWORKING AND RISK -TAKING ON GROWTH OF SELECTED KENYA EXPORT FIRMS: AN ANALYSIS." International Journal of Research - Granthaalayah, 6(4), 351-356. https://doi.org/10.29121/granthaalayah.v6.i4.2018.1672.

\section{Introduction}

Growth is known as a revenue generation, value addition, and expansion in terms of volume of the business. Belderbos et al. (2010) and Moghaddam et al. (2011) postulated that exporting plays a vital role in the world as export has great effects on countries in terms of enhancing economic 
growth and activity, increasing the internal production, reducing the unemployment rate, supplying foreign currencies for import, becoming growth accelerator, making favourable balance of trade, enhancing trade balances and industrial development, improving capacity utilization and productivity and providing employment. The researcher thus deduces that one of objectives of most firms and national governments is to expand exports and that exporting may be considered a fundamental strategy in ensuring firms' survival or growth. The vital role which export trade plays in the economic growth of countries, Kenya included, also causes the researcher to posit that knowing factors which may influence growth of export firms, is key as their application may contribute to firms' growth, that may ultimately contribute consistently to economic growth.

ROK $(2008,2016)$ state that Kenya pursues export oriented economic growth, with emphasis laid on value addition on products, innovation of firm processes, export market diversification and industrial transformation. Presently in Kenya economic development is export trade led because, there is more benefits that are gained from export of goods and services to other countries (ROK, 2016). The contribution of export trade is important in increasing, volume of sales and number of employees of firms and reduction of poverty levels. Despite the recognition of the importance of export trade by the Kenya government $70 \%$ of Kenyan exports were to 12 markets only and relies mainly on five main products (ROK, 2016).

Cisi et al. (2016) present that according to Parker (2008) a business network is a group of entrepreneurs that voluntary share knowledge and experiences. For the purpose of this study, networking is a deliberate action by an entrepreneur to collaborate with other entrepreneurs for purposes of gaining business information and other resources for business growth.

Risk taking propensity is was studied by De Haan (2010) quotes Brockhaust Sr. (1980) who defined risk-taking propensity as perceived probability of receiving rewards associated with success of a proposed situation required before embarking on a venture. For the purpose of this study, the researcher adopts definition of risk taking propensity as the tendency of a decision maker either to take or to avoid risks. Risk Taking Propensity and Firm Growth Risk- taking refers to a firm's willingness to engage in calculated business- related risks in the market place, even when their outcomes are uncertain (Lumpkin and Dess, 2012). Firms with risk taking behaviour are described as being bold and aggressive in pursuing opportunities, as they are ready to incur large resource commitments in the hope of obtaining high returns (Miller, 2011). Risk -taking behaviour consists of activities such as borrowing credit heavily, venturing in unknown markets and committing a high percentage of resources to projects with uncertain outcomes (Kusumawardhani, 2013).

Naldi et al. (2007) also found a negative relationship between risk- taking behavior and performance of Swedish Small and Medium Enterprises. Kasumawardhani (2013) in a study on the role of entrepreneurial orientation in firm performance based on Indonesian Small and Medium Enterprises in the furniture industry revealed that all entrepreneurial dimensions, except risk taking contribute positively to firm performance. The findings of the various studies mentioned indicate that effect of risk taking, as a dimension of entrepreneurial orientation on firm growth is not conclusive. Therefore, there exists literature gap, which this study set to examined.

\section{Networking and Firm Growth}


Prapah (2011) argued that the importance of networks could not be overemphasized because of their role in developing the private sector in contributing to gross domestic product, employment creation and raising income levels through its spill over effects. The scholar further posit that an entrepreneur's network's position reveals its ability to access information and knowledge, that is transformed into production of new products and improving upon existing ones. Cisi et al. (2016) posit that business network is a group of entrepreneurs that voluntary share knowledge and experiences. According to the scholars, the relationships among firms in the network are closer, have clear objectives and respect a specific contractual scheme, Firms enter this type of legal contract voluntarily with the explicit aim of co-producing, co-marketing, co-purchasing or cooperating in product or market development.

Karabag et al. (2012) findings of a study on determinants of firm competitiveness of Turkish textile and apparel exporters showed that networking scored lowest average (3.4) in relationship with firm growth. Networking in the study measured as industry cooperation and clustering, networking with politician and state employees played little role in improving competitiveness. Karabag et al. (2012) posited that the study findings contradicted some earlier studies; Harrigan (1987 and 1988); Li and Zhou (2008)Alvarez et al. (2009) and Jean et al. (2011) whose study findings showed that networking significantly improves firm competitiveness. The researcher argues that firm competitiveness ensures frim growth that is if a firm has competitive advantage due to its competitiveness, a firm is most likely to increase market share, which culminates into firm growth. The difference in the study findings indicates literature gap, which this study set to examine to reveal more in-depth insights and bridge the knowledge gap.

\section{Methodologies}

\section{Design, Target population and Sample size}

This Research employed cross sectional survey research design using Mixed (quantitative and qualitative) approaches. The target population whose data was adopted from the $\mathrm{PhD}$ thesis by Achola, J.,O., (2018), data was collected by questionnaires from Selected Kenya Export Firms. It was conducted based on data collected from selected export firms in selected towns, namely; Eldoret, Mombasa, Nairobi, Naivasha and Thik. in Kenya

\section{Analysis Techniques, Methods, Findings and Discussions}

Normality, Skewness and Kurtosis: Skewness refers to the symmetry of a distribution whereas Kurtosis relates to the peakedness of a distribution. A distribution is said to be normal when the values of skewness and Kurtosis are equal to zero (Tabachnick and Fidell, 2001). However, there are few clear guidelines about how much non-normality is problematic, this study adopted guideline by Information Technology Services, (2006) and (Hui, 2011:p120; Ananda, 2012; Sanja, 2017) approach, the study also employed Bollen-Stine bootstrap and associated p-value was considered in this study as demonstrated in chapter4. It is suggested that absolute values of univariate skewness indices greater than $3.0 \mathrm{~s}$ Innovation $\mathrm{m}$ to describe extremely skewed data sets.

Table 3.1: Kurtosis Value Parameters 


\begin{tabular}{|l|l|}
\hline Kurtosis Index & Levels \\
\hline$>10$ & Severe non-normality Distribution \\
\hline 3.5 to 10 & Non-normality Distribution \\
\hline 1 to 3.5 & Moderate Non-normality Distribution \\
\hline$<1$ & Negligible non-normality Distribution \\
\hline 0 & Normal Distribution \\
\hline
\end{tabular}

Source: Information Technology Services (2006)

In this study utilised (Amos 23.0) which provides normality checks for data including skewness, Kurtosis indexes and Mardia's coefficient which is a test of multivariate normality. Critical ratios provided by Amos output as attached to Kurtosis represents Mardia's normalized estimate of multivariate Kurtosis. Bentler (2005) suggested that, in practice, values $>5.00$ are indicative of data that are non-normally distributed. To correct for non-normality in the Underlying database, use of Bollen-Stine bootstrap and associated p-value was considered in this study. For all constructs to moderate the effect of multivariate non-normality, the maximum likelihood (ML) estimation, which is relatively robust against departures from multivariate normality even in a small manner (Anderson and Gerbing, 1988; Innovation, 2000; Tabachnick and Fidell, 2001; Hui ,2011; Sanja, 2017; p169), was applied with Bollen-Stine bootstrap procedure. The bootstrap sample of 1000 was adopted.

\section{Networking, Risk Taking Propensity \& Export Firms Sub Models by Bootstrapping}

The bootstrap confidence intervals are presented in (Table 4.19). The bias-corrected confidence intervals are used because these intervals are considered to yield more accurate values than percentile confidence intervals (Efron and Tibshirani, 1993, Hui,B., 2011, Arbuck , 2013, p298).The confidence intervals for Networking, Risk taking propensity \& the usage of Growth of Export Firms do not include zero. The value of $p$ in the ' $p$ ' column of (Table 4.19) indicates that a 100 (1-p) \% confidence interval would have one of its end points at zero. In this sense, the pvalue can be used to test the hypothesis that an estimate has a population value of zero (Hui, 2011, Arbuck, 2013:p300). In this case the relationship between export firms and (service Quality) Risk taking propensity has a p-value 0.07, Export Firms and Networking S2 has a p-value 0.05 which means that a $94 \%$ confidence interval would have a lower boundary at zero. In other words, a confidence interval at any level less than $94 \%$ such as $90 \%$ or $92 \%$ would not include zero, and therefore reject the hypothesis that the regression weight is zero for a $90 \%$ confidence interval.

Table 4.1: Bootstrap on Confidence intervals of Networking and Risk taking propensity

\begin{tabular}{|ll|l|l|l|l|}
\hline Parameter & Estimate & Lower & Upper & P \\
\hline Risk taking propensity & 1 & 313.21 & 307.86 & 318.02 & 0.000 \\
\hline Risk taking propensity & 2 & 24.87 & -1.31 & 49.79 & 0.070 \\
\hline Risk taking propensity & 3 & 2827.03 & 2393.34 & 3253.49 & 0.000 \\
\hline Networking S1 & 64.76 & 50.28 & 78.19 & 0.000 \\
\hline Networking S2 & 34.87 & -1.21 & 59.79 & 0.050 \\
\hline Networking S3 & 3827.01 & 2091.34 & 3353.49 & 0.000 \\
\hline Export Firms 1 & 64.76 & 50.28 & 78.19 & 0.000 \\
\hline Export Firms 2 & 22.82 & -1.31 & 49.09 & 0.060 \\
\hline Export Firms 3 & 3427.03 & 1091.34 & 1353.49 & 0.030 \\
\hline
\end{tabular}

Assessing Confidence Intervals by Bootstrap: Risk Taking Propensity \& Export Firms 
The values in (Table 4.2) Standardized Parameter are very small for most of the cases and positive values indicate that the estimates of the bootstrap samples are higher than the original maximum likelihood estimates, while negative vales indicate lower original maximum likelihood estimates. The low bias indicates that the maximum likelihood estimates and the bootstrap estimates are very close to each other. The last column, labeled SE-Bias, reports the approximate standard error of the bias estimate. For the majority of the cases the estimated bias is smaller in magnitude than its standard error. This indicates that there is little evidence that the regression weights are biased.

The values in (Table 4.2) Standardized Parameter are very small for most of the cases and positive values indicate that the estimates of the bootstrap samples are higher than the original maximum likelihood estimates, while negative vales indicate lower original maximum likelihood estimates. The low bias indicates that the maximum likelihood estimates and the bootstrap estimates are very close to each other. The last column, labeled SE-Bias, reports the approximate standard error of the bias estimate. For the majority of the cases the estimated bias is smaller in magnitude than its standard error. This indicates that there is little evidence that the regression weights are biased.A Study by L Innovation and Kimhi, (2005) in establishing the maximum likelihood, bootstrapping and asymptotic distribution Innovation estimations employed LISRAEL . The analysis treated ordinal variables as continuous. They further argue that while estimating structural equation models with ordinal variables is possible in certain software packages, however this study utilized AMOS to analyse Bootstrapping; it greatly simplifies the difficulty of the estimation process.

Though each of the mentioned methods; ML, bootstrapping, ADF, and Mplus, have their limitations, to the extent that each give consistent results, the confidence in the results increase. Andreassen, et al.(2006) used a similar approach in analyzing bank satisfaction data; the authors conclude that such "estimation triangulation" provides a useful means of assessing model misspecification. To assess the quality of a Growth_of_Export Model specification (i.e. how well the model-implied variance-covariance matrix compares to the sample variance-covariance matrix), some measure of goodness-of-fit is $\mathrm{n}$ Innovation. Certain transformations of the chisquare statistic are universally used for such a measure, including the chi-square statistic divided by the model Degree, goodness-of-fit index (GFI), normed fit index (NFI), and comparative fit index (CFI). Other measures, such as the root-mean square error of approximation (RMSEA) are also recommended by various scholars. An entire body of literature is devoted to assessing the performance of goodness-of-fit measures under a host of conditions (e.g., Lei and Lomax, 2005). Most structural equation model software packages present numerous goodness-of-fit measures as part of their standard reporting (Byrne, 2001; Ullman, 1996; West et al., 1995; Satorra and Bentler 1988, 1994).

\section{Conclusion}

The analysis on the study demonstrates that strategic entrepreneurial orientation dimensions of Risk taking propensity has a negatitive contribution to growth of selected export firms in Kenya, while networking has a positive contribution to growth of selected export firms in Kenya. The findings substantiate the conceptual framework of the study. The analysis reveals that application of Networking is useful in growth of a firm. This is more so due to today's business environment that is characterized with competition and ever-changing consumer preferences. New product, 
process and distribution technologies provide significant levers for creating competitive value. Dogan (2017) quoted Ahmed

\section{Recommendation Future Studies}

Kenya National export development and promotion strategy should be enhanced by formulating strategic objective on entrepreneurial inclination. Activities under such an objective would ensures that application of Networking and hence Risk-taking propensity should be further investigated in the process of promotion of export trade. The current strategy does not include an aspect of application of strategic entrepreneurial orientation dimensions. Future studies on export firms should use larger samples to validate these results, the study is limited to Kenya, and hence it is recommended that similar study be conducted in other developing countries.

\section{References}

[1] Adewale, G, Adesola, M.A, Oyewale, I.O (2013). Impact of Marketing Strategy on Business Performance: A study of selected Small and Medium Enterprises in IOSR Journal of Business andManagement (IOSR-JBM). E-ISSN: 2278-487X, p-ISSN: 2319-7668. Volume 11, Issue 4 (Jul. - Aug. 2013), PP 59 -66. www.iosrjounals.org.

[2] Adewale, G., Adesola, M., \& Oyewale, I. (2013). Adewale, G,; Adesola, M.A; Oyewale , I.O.;. Impact of Marketing Strategy on business performance.

[3] Ahmed, K, Shepherd, D. (2010). Innovation Management: Context, Strategies, Systems and processes, 1st ed., Harlow: Pearson Education.

[4] Alvarez, ,., \& Barney, ,. (2007). Discovery and creation: Alternative Theories of Entrepreneurial action, dezembro 2007, Ohio. Organizacoes em context, 3, n.6. Alves, P, Draper, P, Khumalo, N. (2009). African challenges in International Trade and Regional Integration: What Role for Europe. Occasional Paper No 32, Eu- Africa project. South African Institute of International Affairs.

[5] Amarjit Gill (2012). Barriers to Small Business Growth in Canada. Journal of Small Business and enterprise Development; Vol, 19 issue: 4, pp.656-688,

[6] https://doi.org/10.1108/1462001211277451.

[7] Ananda Kumar Palaniappan, (2012). University of Malaya, Faculty of Education, Tel: 0199310956; 03-79675046. Prof. Dr. Ananda Kumar Palaniappan (PhD) education Email:ananda4989@yahoo.com;anandak@um.edu.my

[8] Cabrera, R.V. Perez- Luno, A, Wiklund, J (2007). Innovation and Imitation as Source of Sustainable Competitive advantage, Management Research, Vol 5, no.2 (Spring 2007). M.E. Sharpe, Inc. ISSN 1536-5333/2007

[9] Casillas, J. C. Moreno, A.M. Barbero, J.L. (2010). A configurational Approach of the Relationship between Entrepreneurial orientation and growth of Family Firms. Family Business Review, 23(1) 24-44.

[10] Choi, R, Shepherd, D. (2010). Entrepreneurs Decision to Exploit. Journal of management, 5 Covin, J. G. \& Slevin, D.P. (1991). A Conceptual Framework of Entrepreneurship as a Firm Behaviour. Entrepreneurship Theory and Practice, 14(1) 7-26.

[11] Covin, J. G. \& Slevin, D. P. (2006). Strategic Process Effects on the Entrepreneurial OrientationSales Growth Rate Relationship. Entrepreneurship Theory and Practice, 30 (1), 57-81.

*Corresponding author.

E-mail address: pkibas@gmail.com/rotuya@yahoo.com/1joyceachola@ yahoo.com 